\title{
Evaluation of Safety and Efficacy of Barrier Foam Dressing in Patients with Exuding Wounds
}

\author{
Madhuri Gore ${ }^{1 *}$, Shashank Jadhav ${ }^{2}$, Gregory Schultz ${ }^{3}$ and Dilip Mehta ${ }^{4}$ \\ ${ }^{1}$ Consultant General Surgeon, Zen Multi Speciality Hospital, India \\ ${ }^{2}$ Medical Director, Viridis BioPharma Pvt Ltd, India \\ ${ }^{3}$ Quick-Med Technologies, Inc, Florida, United States \\ ${ }^{4}$ CEO and Chairman, Viridis BioPharma Pvt Ltd, India
}

*Corresponding author: Madhuri Gore, Consultant General Surgeon, Zen Multi Speciality Hospital, Chembur, Mumbai, Maharashtra 400071 India

\section{ARTICLE INFO}

Received: 幽 February 04, 2021

Published: 㓞 February 15, 2021

Citation: Madhuri Gore, Shashank Jadhav, Gregory Schultz, Dilip Mehta. Evaluation of Safety and Efficacy of Barrier Foam Dressing in Patients with Exuding Wounds. Biomed J Sci \& Tech Res 33(5)-2021. BJSTR. MS.ID.005475.

Keywords: Barrier wound dressing; Ammonium Polyquaternary compound poly(DADMAC); NIMBUS® Technology; Exuding wound; Nosocomial Infection

\section{ABSTRACT}

Objective: The study was conducted to evaluate the safety, efficacy and tolerability of Barrier Foam Dressing (BFD) combined with ammonium Polyquaternary compoundpoly(DADMAC) with regard to effect on wound characteristics i.e., size, discharge, granulation; extent of dressing breakthrough in exuding wounds, pain and time to wound closure by epithelization or readiness for secondary suturing or skin grafting.

Material and Methods: The study was an open labeled single center trial of 30 patients with wound or wounds of different etiologies. The patients satisfying inclusion and exclusion criteria as specified in the protocol approved by the Ethical Committee, were enrolled. The wound was evaluated on the basis of size, discharge and granulation at baseline and on every 8th day along with wound photograph till the end point. Microbial analysis of the wound swab and pain score (using Visual Analog Scale - VAS) was recorded at baseline and at the end point of study. Improvement in wound healing was observed by contraction of wound, reduction in exudate, wound debridement and as wound epithelisation, or granulation tissue formation that makes the wound ready to receive a skin graft.

Results: BFD was observed to have good ability to absorb wound exudate, help separation of necrotic tissue making debridement easier. Minimal adherence was noticed while removing the dressing. There was no need of any topical antimicrobial along with this dressing. Biochemical and microbiological variables also exhibited the safety and efficacy of this dressing. Its application on skin surface was well tolerated without side effects or local reaction by all except one of the patients.

Conclusion: The BFD can be used as a primary dressing for various types of wounds and has favorable influence on wound healing process with good tolerance.

\section{Introduction}

The purpose of wound dressing or cover is to provide moist environment, reduce bioburden, promote granulation and epithelisation, shorten duration of inflammatory response, be useful as primary wound dressing and to prevent nosocomial infection. A Nosocomial Infection or Healthcare-associated infection (HAI) is defined as any clinical infection that was neither present nor was in its incubation period when the patient entered the hospital [1]. Nosocomial infection occurs in both adult and pediatric patients [2].
In a review by Ramasubramanian, incidence of HAI was observed to vary from $11 \%$ to $83 \%$ in India [3]. In another study conducted in 204 patients admitted in hospital, 36 patients developed HAI [4]. The Surgical site infection (SSI) incidence was $0.5 \%$ to $20 \%$ depending on type of operation and underlying patient status [3]. The incidence of SSI in 2011 was around 21\% [5] and in 2012 it was around 16\% [6]. In a study conducted in Northern India, out of 153 patients 87 (58.86\%) patients had acquired HAI [7]. Incidence in 
Southern India was found to be $41 \%$ [8]. Barrier wound dressings such as foam and gauze are the most commonly used dressings for the prevention of cross contamination and to provide the proper wound healing environment. In India many types of wound dressings are available for example traditional wound dressing (such as gauze, film, bandages, lint), modern wound dressing (including film, foam, hydro gel, hydrocolloids), semi-permeable film dressing, semi-permeable foam dressing, Alginate dressing, Bioactive wound dressings, Tissue engineered skin substitutes, Medicated dressings, Composite dressing [9]. The dressings are either without any antimicrobial or with embedded antimicrobial that forms an active layer between wound and dressing. In these drug eluting dressings, the antimicrobial leaches out of the dressing and into the wound environment.

Barrier Foam Dressing (BFD) is based on the patented NIMBUS $^{\circledR}$ Technology. BFD is a highly absorbent polyurethane foam specially treated with quaternary ammonium compound poly(DADMAC)). It has long chain polymers (molecular weights of greater than $100,000 \mathrm{Da}$ ) with high densities of quaternary amines poly(DADMAC) attached to its surface so that it does not permit leaching of polymer from the dressing into the wound. Such polymeric quaternary amines have shown to play a vital role as a surface-active agent [10]. The current study aims to evaluate the efficacy, tolerability and safety of BFD in the management of exuding wounds and ulcers.

\section{Materials and methods}

\section{Study Design}

An open labeled study was conducted to evaluate the efficacy, tolerability and safety of BFD in the treatment of exuding wounds and ulcers. Approval was obtained from Independent Ethics Committee (Intersystem BioMedica Ethics Committee, Mumbai, India) before study initiation and was registered with CTRI (CTRI/2012/09/002996). Informed consent was obtained from the patients either examined or admitted at Joy Hospital, Chembur, Mumbai, India before screening and enrollment in the trial.

Inclusion Criteria: Exuding wound, Study ulcer of minimum size $5 \mathrm{~cm}^{2}$, Ankle brachial index (ABI) greater than 0.7 , Minimum age of 18 years.

Exclusion Criteria: History of substance abuse within the previous year, seropositive status, treatment with systemic corticosteroids, immunosuppressive agents, radiation therapy or chemotherapy within last 30 days or Glycosylated hemoglobin (HbA1C) more than $10.0 \%$.

Primary Outcomes: The primary objective of this study was to evaluate BFD with regard to: Effect on wound characteristics i.e., size, discharge, granulation, incidence of breakthrough in exuding wounds and microbiology of wound. The end point was assessed as the time to wound closure by epithelization or readiness for secondary suturing or split thickness skin grafting (STSG).
Statistical Analysis: The test used to calculate statistical analysis was students t-test by using Graph pad prism 5 .

\section{Methodology}

In this open labeled trial 30 eligible patients were subjected to laboratory screening tests for inclusion after obtaining the written informed consent. Patients meeting the inclusion criteria were enrolled in the study. Detailed case history was recorded. This included medical history, physical examination, vital signs and medication history. ABI was noted along with the physical examination. Swab for microbial analysis (for Staphylococcus aureas, Streptococcus pyogenes, Escherichia coli, Pseudomonas aeruginosa) was obtained. One clinical photograph of the wound site was taken at enrollment. In addition, a regional photograph was also taken that indicated the location of the ulcer on the body. The wound was evaluated for size, discharge, granulation and peri wound skin status, and a wound size tracing was made. Surgical wound debridement was performed as appropriate before enrollment. Pain score was evaluated based on Visual Analog Scale (VAS) during every visit. Clinical assessment for pain, tenderness, erythema, and edema was done. During the intermediate visits (every alternate day e.g., day 2, day 4 ...) the dressing was changed. The breakthrough i.e., permeation of discharge through the dressing was evaluated as complete, incomplete, and partial followed by physical examination along with vital signs and medication history.

Surgical debridement was carried out if required. During the weekly visits (day 8 , day 16 , etc. \pm 1 day) the same protocol as at intermediate visits was implemented. One photograph of the wound was taken before debridement if debridement was needed. Wound size was traced at each weekly visit. Viridis Biopharma Pvt. Ltd. supplied BFD (size of $10 \times 10 \mathrm{~cm}$ ) under licensing from QuickMed Technologies, Inc. packed in alu-pet. In all the subjects, the BFD was removed every alternate day. The end point was defined as the day the wound was epithelised or was ready for secondary suturing or STSG. At the end point all the procedures performed during weekly visits were repeated. Extent of reduction in wound size was calculated. The wound care protocol followed for all the wounds was uniform. The steps were: Wound cleaning with saline, Debridement if needed after photograph, Application of BFD cut to size, Secondary dressing of sterile gamjee-single pad and fixation of dressing with Tape or bandage.

\section{Results}

Out of the 30 screened subjects, 1 was screen failure (individuals who undergo screening but are not enrolled in a clinical trial). Out of 29 enrolled patients 5 were females. Three patients had to be excluded from the analysis due to the reasons detailed below. Hence 26 out of 29 enrolled patients have been considered for analysis. Table 1 shows the patient distribution according to etiology of wound and their flow in the study. Diabetic foot ulcers were present in 13 wounds (44.8\%) while complex skin 
and soft tissue infection (CSSTI) was the cause of wound in 16 (55.2 $\%)$. The wounds included under CSSTIs category included bed sore, vasculitic and venous ulcers, accidental wounds, surgical site infection, amputation stumps and Fournier's gangrene. Out of 29 enrolled subjects, majority of patients i.e.,23 (92.3\%) had wound on foot or leg. The remaining 6 wounds were on varied body areas 2 on sacrum, 1 each on abdomen, scalp, back and scrotum.

Table 1: Showing the patients with different wound etiologies and their study flow.

\begin{tabular}{|c|c|c|c|}
\hline & $\begin{array}{c}\text { Diabetic } \\
\text { foot ulcers } \\
\text { (DFU) }\end{array}$ & $\begin{array}{c}\text { Complex skin \& } \\
\text { soft tissue infection } \\
\text { (CSSTI) }\end{array}$ & Total \\
\hline Screened & $14(46.6 \%)$ & $16(53.3 \%)$ & $30(100 \%)$ \\
\hline Screen failure & 1 & Nil & 1 \\
\hline Enrolment & $13(44.8 \%)$ & $16(55.2 \%)$ & $29(100 \%)$ \\
\hline Withdrawn & 2 & 1 & $3(10.3 \%)$ \\
\hline Evaluated & $11(42.3 \%)$ & $15(57.7 \%)$ & $26(100 \%)$ \\
\hline Failure declared & 2 & 1 & $3(11.5 \%)$ \\
\hline Successful & 9 & 14 & $23(88.5 \%)$ \\
\hline
\end{tabular}

The Reasons for Exclusion from Analysis were as follows:

Withdrawn before first visit - 3 (Excluded from analysis)

A. Patient ID No ST 02 - Pain, Excoriation - Venous ulcer

B. Patient ID No AG 07 - Transferred to other health care facility - Diabetic foot ulcer

C. Patient ID No BJ 13 - Change of thought after screening with self-withdrawal- Diabetic foot ulcer.

Follow up failure after second visit was encountered in 2 patients. Hence telephonic follow up was resorted to

A. Patient ID No SB 15 - Sacral CSSTI - Reported wound epithelisation

B. Patient ID No BM 19- Scalp CSSTI - Reported wound epithelisation

These patients have been included in the analysis.

The reasons for declaring failure and hence trial termination after more than 3 visits was decided in 3 patients for following reasons

A. Patient ID No MA 10: Diabetic foot ulcer - Amputation of wound bearing toe understudy - After visit 5 .

B. Patient ID No JS 25: Venous ulcer - No change after 64 days.

C. Patient ID No AP 29: Diabetic foot ulcer - No improvement after 22 days.

One out of 3 venous ulcers had to be withdrawn from the study in less than one week due to allergic reaction in the peri ulcer skin with severe pain. One more patient with venous ulcer was declared as treatment failure due to lack of any wound improvement despite the use of trial dressing for 64 days as mentioned above. Figures 1A \& 1B shows complete breakthrough in one subject of diabetic foot ulcer at the assessment at one week and no breakthrough on day sixteen. This depicts reduction in wound exudate under BFD. There was overall improvement in the status of all the evaluable 23 wounds by end point achievement. The improvement was observed as reduction in size of wound (Figure 2), reduction in edema and exudate, separation of slough and development of granulation tissue which made the wound ready for receiving STSG or secondary suturing or wound epithelisation. It was observed that BFD had particularly good ability to absorb wound exudates (mild to moderate) and helped separation of necrotic tissue making debridement less frequent and easier when needed. Only 2 patients on one occasion each needed surgical debridement. The improvement in wounds of different etiologies from enrolment to end point has been depicted in Figures 3-7. The pain score varied in different patients within the range of 3 to 7 at the baseline. The average pain score as measured on VAS at baseline was 6-7. The pain score reduced to $1-2$ by the end point. Table 2 shows the range and mean of pain score at enrollment and end point evaluated on the basis of VAS in different type of ulcers.
A

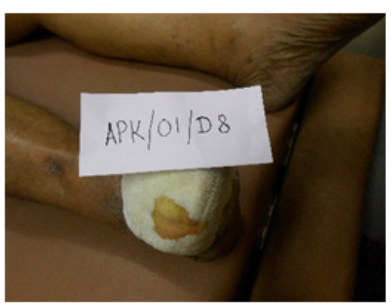

B

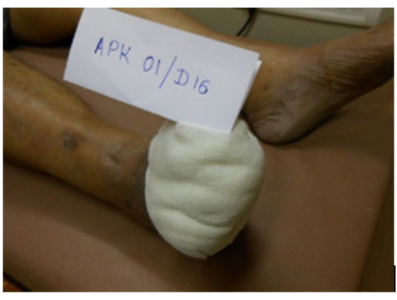

Figure 1: Breakthrough in Subject APK 01 with diabetic foot ulcer - Complete breakthrough on Day 8 (A), No breakthrough on Day 16 (B).

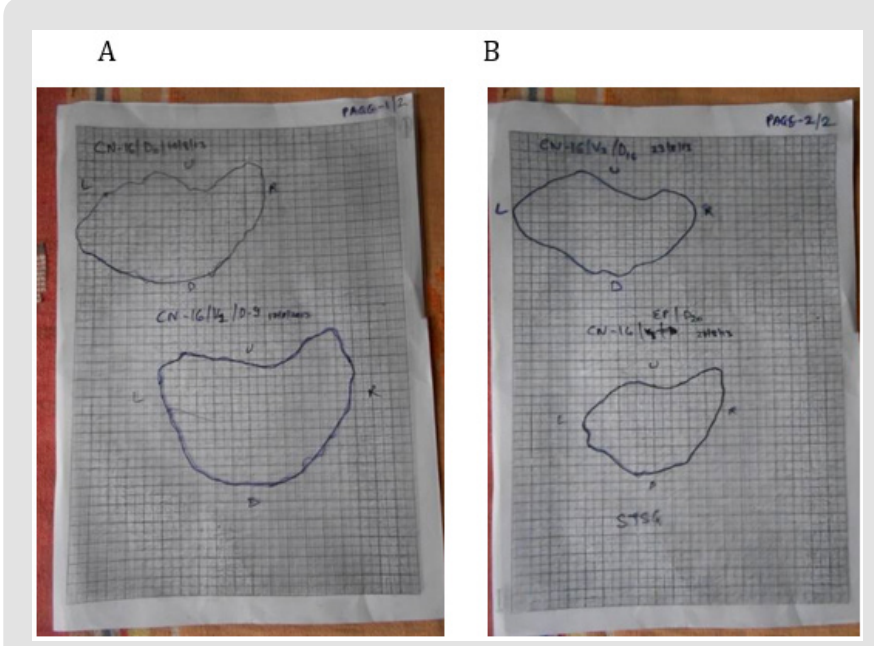

Figure 2: Wound measurement chart for Subject No C N 16 showing wound size reduction. 


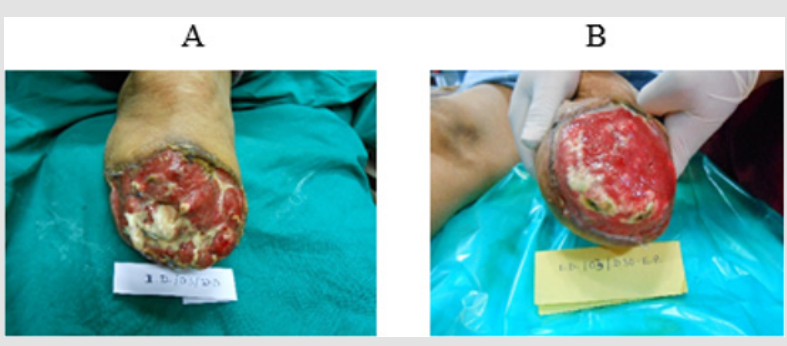

Figure 3: Wound improvement in amputation stump.

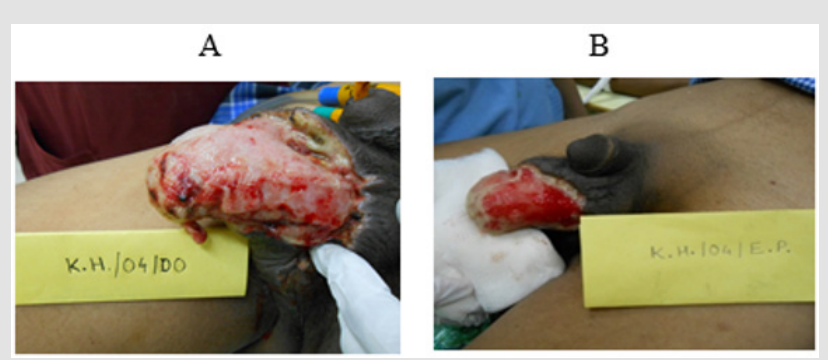

Figure 4: Wound improvement in Fournier's gangrene.

A

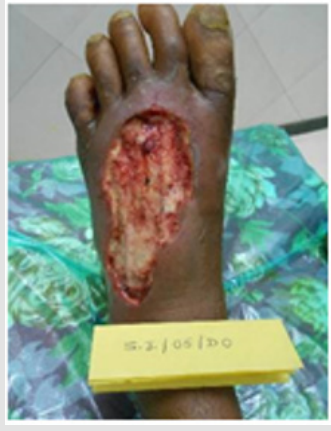

B

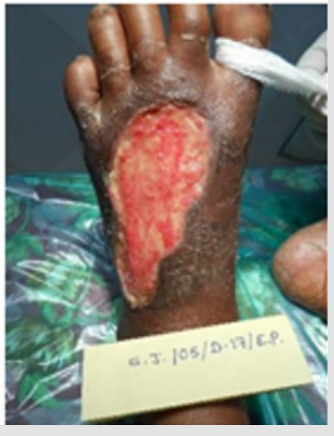

Figure 5: Wound improvement in diabetic foot ulcer.

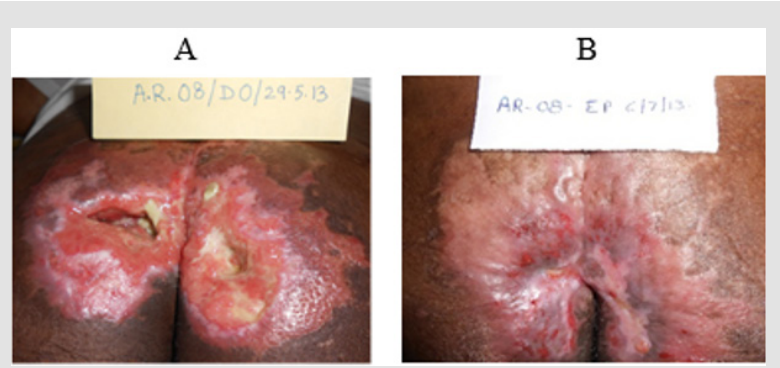

Figure 6: Wound improvement in sacral sore.

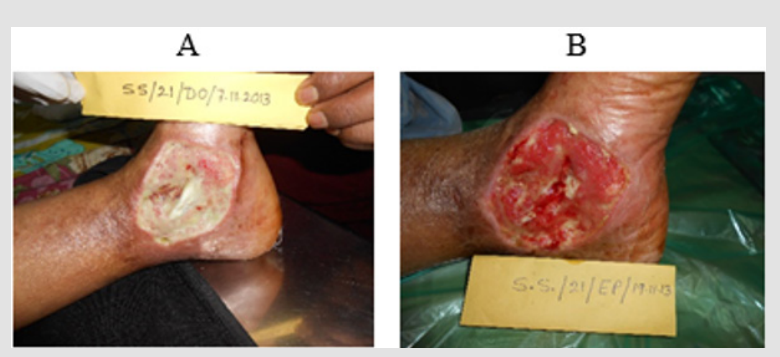

Figure 7: Wound improvement in vasculitic ulcer.
The average reduction in wound size at end point was $60 \%$ in CSSTI while it was observed to be $38 \%$ in patients with diabetic foot ulcer (Table 2). The average reduction in wound size at end point was $60 \%$ in CSSTI while it was observed to be $38 \%$ in patients with diabetic foot ulcer which was statistically significant (Table 2). Maximum wound size reduction was observed to be 98 $\%$ in a sacral bed sore. Table 3 shows the duration taken to reach the end point in wounds of different etiologies. The difference in duration between CSSTIs and DFUs wounds to reach the end point is statistically insignificant value. Two patients failed to follow up after second visit, on telephonic follow up both the wounds were reported to have epithelised and wound photos sent by relatives on mobile were observed for confirmation. Table 3 provides the method of achieving wound closure in the patient population analyzed in the study. The majority (56.52\%) of the patients required STSG to achieve wound closure. The take of split thickness skin graft was $100 \%$ in all patients undergoing STSG indicating optimal wound bed preparation under BFD application. Tables $4 \& 5$ shows the comparison of the wound swab analysis report performed during enrollment and at the End point. The organisms which were found positive in the analysis of the wound swab taken at enrollment were E. coli and Pseudomonas species. In wound swab, the organism which were found to be positive during analysis was E. coli and Pseudomonas species. They were found to be absent in the wound swab taken at the End Point.

Table 2: Showing the effect on pain score and wound size \% reduction achieved in two groups.

\begin{tabular}{|c|c|c|}
\hline Observation & DFU (9 Patients) & CSSTI (14 Patients) \\
\hline $\begin{array}{c}\text { Pain score (VAS) } \\
\text { Enrollment }\end{array}$ & Mean: 6 & Mean: 5.4 \\
Range: $5-7$ & Range: $3-7$ \\
\hline Pain score (VAS) End point 7 & Mean: 1.4 & Mean: 1.2 \\
& Range: $1-2$ & Range: $1-2$ \\
\hline $\begin{array}{c}\text { Wound size \% reduction } \\
\text { Mean } \pm \text { SD }\end{array}$ & Mean reduction & Mean reduction \\
& $38.09 \pm 7.02^{*}$ & $60.89 \pm 8.34^{*}$ \\
\hline
\end{tabular}

Table 3: Showing the Duration taken to reach the end point in wounds of different etiologies.

\begin{tabular}{|c|c|c|}
\hline Duration to end point & DFU & CSSTI \\
\hline Mean & 28.71 Days & 28.50 Days\# \\
\hline Median & 11.53 Days & 22.62 Days \\
\hline Range & 17 to 57 Days & 8 to 39 Days \\
\hline
\end{tabular}

\#P value $<0.4880$ Not significant

Table 4: Showing the method of achieving wound closure in wounds of different etiologies (Total 23 patients as 3 out of 26 were declared failure)

\begin{tabular}{|c|c|c|c|}
\hline $\begin{array}{c}\text { Method of Wound } \\
\text { Closure }\end{array}$ & $\begin{array}{c}\text { Diabetic } \\
\text { Foot Ulcer } \\
\text { (DFU) }\end{array}$ & $\begin{array}{c}\text { Complex Skin } \\
\text { \& Soft Tissue } \\
\text { Infection (CSSTI) }\end{array}$ & Total \\
\hline Epithelisation & Nil & 6 & $6(26.09 \%)$ \\
\hline Secondary Suturing & 2 & 2 & $4(17.39 \%)$ \\
\hline STSG & 7 & 6 & $13(56.52 \%)$ \\
\hline Total & $9(39.13 \%)$ & $14(60.87 \%)$ & $23 \%$ \\
\hline
\end{tabular}


Table 5: Comparison of the wound swab analysis report performed during enrollment and at the End point.

\begin{tabular}{|c|c|}
\hline Enrolment & End point \\
\hline SPECIMEN: Wound Swab & SPECIMEN: Wound Swab \\
\hline METHOD: & METHOD: \\
\hline $\begin{array}{l}\text { Specimen received in a sterile container } \\
\text { was cultured on blood, MacConkey's \& } \\
\text { specialized media. }\end{array}$ & $\begin{array}{l}\text { Specimen received in a sterile } \\
\text { container was cultured } \\
\text { on blood, MacConkey's \& } \\
\text { specialized media. }\end{array}$ \\
\hline SMEAR EXAMINATION: & SMEAR EXAMINATION: \\
\hline $\begin{array}{l}\text { Gram's Stain: Gram negative bacilli } \\
\text { detected }\end{array}$ & $\begin{array}{l}\text { Gram's Stain: No or } \\
\text { Occasional Gram-negative } \\
\text { bacilli detected }\end{array}$ \\
\hline CULTURE REPORT & \\
\hline COMMON ORGANISMS ISOLATED: & CULTURE REPORT \\
\hline $\begin{array}{l}\text { (At the end of } 24 \text { hours of incubation at } \\
\text { 370C) }\end{array}$ & $\begin{array}{l}\text { COMMON ORGANISMS } \\
\text { ISOLATED: }\end{array}$ \\
\hline 1. Escherichia coli & $\begin{array}{l}\text { (At the end of } 24 \text { hours of } \\
\text { incubation at } 370 \mathrm{C} \text { ) }\end{array}$ \\
\hline 2. Pseudomonas species & None \\
\hline
\end{tabular}

\section{Discussion}

The common problem with majority of currently available dressings is they cannot be used as a primary dressing. They need application of one of the topical antimicrobial agent or hydro gels beneath the primary dressing. It is now known that most of the primary antimicrobial impregnated dressings which are applied with the secondary barrier dressing loose their effectiveness over a period due to leaching and hence make the dressing ineffective, wound healing more difficult and prolonged. The persistent inflammatory response contributes to delayed healing of wound and increase in bioburden [11-14]. Commonly used antimicrobial agents have been found to be ineffective in reducing this bioburden [15-17]. Hence there is a need of effective antimicrobial barrier dressing which can be used as a Primary dressing but will not leach out of the dressing. Gauze Woven dressings are the most widely used wound dressing primarily due to their high absorptive capacity, easy availability, and low cost. However, due to their woven structure as well as absorptive nature it is possible for microorganisms, more importantly nosocomial pathogens, to utilize the gauze characteristics and infect wounds. Hence it is necessary to block such bacterial biofilm formation in these wounds [1821]. It has also been shown that these dressings can shed bacteria into the wound and can play a role in cross contamination [19]. Aerosolization of the bacteria on such dressings can contaminate the wards, operating theatres, and burn unit thus playing a role in spreading nosocomial infections $[20,21]$. So, there is a need for dressing that can prevent or minimize this possibility.

The caregiver also needs to consider adherence of the dressing to the wound and surrounding surface. Disturbance of healthy granulation tissue, with attendant pain and extended wound healing times can be the consequences of adherent dressings on the healing wound. There is need of effective antimicrobial barrier dressing which should not result in the disturbance of healthy granulation at the time of removal. Current study demonstrated the safety and efficacy of BFD in exuding wounds and ulcers. All except 2 venous ulcer patients showed improvement in the wound condition as assessed by healthy granulation, pain reduction, absorption, and reduction of wound exudate, decrease in wound size and improvement in peri-wound skin condition. This BFD could be used as primary dressing without topical antimicrobial agent. It did not adhere to wound surface and helped in separation of necrotic tissue. The wound bed preparation achieved was satisfactory as reflected in $100 \%$ success of STSG. The culture from wound swab showed that the organisms grown at Enrollment were absent at the End Point. This is effective in controlling cross infection and nosocomial infection. Only one out of 29 patients enrolled in the trial developed periulcer skin reaction with the use of BFD.

Various studies conducted on BFD demonstrated the inhibition of bacterial growth under the dressing. In a study by Trans PL, et al. [22], pDADMAC-PU dressing produced more than 8 log reduction in biofilm formation by pathogens suggesting pDADMAC-PU to be an effective wound dressing that inhibits the growth of wound pathogens both within the wound and in the wound dressing [22]. Similar results were observed in a in vivo mouse model [23]. Another study conducted by Mikhaylova et al. [24] has shown that BFD does not present any sign of cytotoxicity, is biocompatible, not leachable and possesses antimicrobial activity against host of microorganisms including E. coli, S. aureus, Pseudomonas aeruginosa, Methicillin-resistant Staphylococcus aureus (MRSA) etc. Overall BFD has thus been shown to be a unique dressing for management of wound as well as prophylaxis and prevention of HAI.

\section{Conclusion}

On completion of the study, the Investigators are of the opinion that BFD is eminently suitable for exuding wounds and ulcers considering its safety, tolerability, and efficacy. It is very convenient to use and it is easy to train the patient or relative to use it at home for wound care. This is a very valuable quality in view of large number of patients especially with diabetic foot and CSSTIs in India and the long duration needed for wound healing in these patients. However controlled studies in larger population will help in comparing efficacy and probably establishing superiority of BFD for wound management in comparison with presently available drug eluting dressings.

\section{Declaration of Interest}

This study was sponsored by Viridis BioPharma Pvt. Ltd., Mumbai, India by providing the dressing material including the dressing under trial, proformas, wound size measurement sheets.

\section{References}


1. Monegro FA, Regunath H (2018) Hospital Acquired Infection. Statpearls.

2. Revelas A (2012) Healthcare- associated infections: A public health problem. Niger Med j 53: 59-64.

3. Ramasubramanian V, Iyer V, Sewlikar S, Desai A (2014) Epidemiology of healthcare acquired infection- an Indian prospective on surgical site infection and catheter related blood stream infection. IJBAMR 3: 46-63.

4. Singh SC, Chaturvedi AC, Garg B, Datta RC, Kumar AM (2013) Incidence of healthcare associated infection in the surgical ICU of a tertiary care hospital. MJAFI 69: 124-129.

5. Arikawa T, Kurokawa T, Ohwa Y, Ito N, Kotake K, et al. (2011) Risk factors for surgical site infection after hepatectomy for hepatocellular carcinoma. Hepatogastroenterology 58(105): 143-146.

6. Patel SM, Patel MH, Patel SD, Soni S, Kinariwala DM, et al. (2011) Surgica site infections: Incidence and risk factors in a tertiary care hospital, western India. Nat J Commun Med 3: 193-196.

7. Choudhuri AH, Chakravarty M, Uppal R (2017) Epidemiology and characteristics of nosocomial infections in critically ill patients in a tertiary care intensive care unit of northern India. Saudi J Anaesth 11: 402-407.

8. Ramana BV, Chaudhury A (2012) Device associated nosocomial infections and patterns of antimicrobial resistance at a tertiary care hospital. J Dr. NTR Univ Health Sci 1: 86-89.

9. Dhivya S, Padma VV, Santhini E (2015) Wound dressing- a review. Biomedicine 5: 22

10. Murata H, Koepsel RR, Matyjaszewski K, Russell AJ (2007) Permanent, non-leaching antibacterial surface- 2 : how high density cationic surfaces kill bacterial cells. Biomaterials 28: 4870-4879.

11. Trengove NJ, Stacey MC, Macaulley S, Bennett N, Gibson J, et al. (1995) Analysis of the acute and chronic wound environments: The role of proteases and their inhibitors. Wound Repair Regen 3: 273-283.

12. Yager DR, Chen SM, Ward SI, Olutoye O0, Diegelmann RF, et al. (1997) Ability of chronic wound fluids to degrade peptide growth factors is associated with increased levels of elastase activity and diminished levels of proteinase inhibitors. Wound Repair Regen 5: 23-32.

13. Yager DR, Nwomeh BC (1999) The proteolytic environment of chronic wounds. Wound Repair Regen 7: 433-441.

14. Wright JB, Lam K, Buret AG, Olson ME, Burrell RE (2002) Early healing events in a porcine model of contaminated wounds: Effects of nanocrystalline silver on matrix metalloproteinases, cell apoptosis and healing. Wound Repair Regen 10: 141-151.

15. Patterson JA, Bennett RG (1995) Prevention and treatment of pressure sores. J Am Geriatr Soc 43: 919-927.

16. Findlay D (1996) Practical management of pressure ulcers. Am Fam Physician 54: 1519-1536.

17. Weinstein ML (1998) Update on wound healing: A review of the literature. Mil Med 163: 620-624.

18. Lawrence JC, Lilly HA, Kidson A (1992) Wound dressings and air-borne dispersal of bacteria. Lancet 339: 807.

19. Lawrence JC (1994) Dressings and wound infection. Am J Surg 167: 21S-24S.

20. Bowling FL, Stickings DS, Edwards Jones V, Armstrong DG, Boulton JM (2009) Hydrodebridement of wounds: effectiveness in reducing wound bacterial contamination and potential for air bacterial contamination. J Foot Ankle Res 2: 1-8.

21. Sonnergren HH, Strombeck L, Aldenborg F, Faergemann J (2013) Aerosolized spread of bacteria and reduction of bacterial wound contamination with three different methods of surgical wound debridement: a pilot study. J Hosp Infect 85: 112-117.

22. Tran PL, Hamood AN, De souza A, Schultz G, Liesenfeld B, et al. (2015) A study on the ability of quaternary ammonium groups attached to a polyurethane foam wound dressing to inhibit bacterial attachment and biofilm formation. Wound repair and regeneration 23: 74-81.

23. Tran PL, Huynh E, Hamood AN, De Souza A, Schultz G, et al. (2017) The ability of quaternary ammonium groups attached to a urethane bandage to inhibit bacterial attachment and biofilm formation in a mouse wound model. Int Wound J 14(1): 79-84.

24. Albina Mikhaylova, Bernd Liesenfeld, David Moore, Toreki W, Vella J, et al. (2011) Preclinical Evaluation of Antimicrobial Efficacy and Biocompatibility of a Novel Bacterial Barrier Dressing Wounds 23(2): 24-31.
ISSN: 2574-1241

DOI: 10.26717/BJSTR.2021.33.005475

Madhuri Gore. Biomed J Sci \& Tech Res

This work is licensed under Creative Commons Attribution 4.0 License

Submission Link: https://biomedres.us/submit-manuscript.php

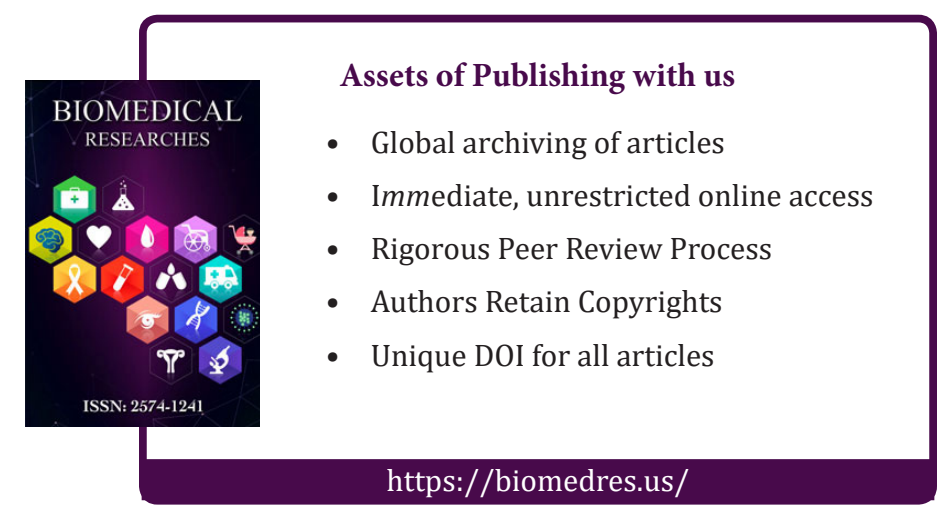

